\title{
EDUCAÇÃO FÍSICA E ESPORTES: MOTIVANDO PARA A PRÁTICA COTIDIANA ESCOLAR
}

\author{
PHYSICAL EDUCATION AND SPORTS: MOTIVATION FOR SCHOOL DAILY \\ PRACTICE
}
EDUCACIÓN FISICA Y DEPORTES: MOTIVACIÓN PARA LA PRÁCTICA ESCOLAR COTIDIANA

\author{
Luciane Cristina Arantes da Costa*, Patricia Carolina Borsato Passos**, \\ Vânia de Fátima Matias de Souza*, Lenamar Fiorese Vieira*
}

Palavras chave: Educação Física. Esportes. Educação.

Keywords: Physical Education. Sports. Education.

Palabras clave: Educación Física. Deportes. Educación.

\begin{abstract}
Resumo: Analisamos como um programa de intervenção baseado no ensino de esportes coletivos pôde contribuir para que os alunos se motivassem a participar das aulas de Educação Física. A ação interventiva sustentou-se em um modelo híbrido de ensino: educação esportiva e desenvolvimentista. Trabalhamos 45 aulas, com a participação de 23 alunos do 60 ano do ensino fundamental. A partir do questionário de Necessidades Psicológicas Básicas na Educação Física Escolar observamos que o programa indicou uma melhora na autonomia, refletindo na participação e integração dos alunos durante a realização das aulas.
\end{abstract}

Abstract: We analyze how an intervention program based on the teaching of team sports could contribute to motivate students to participate in Physical Education classes. The intervention was based on a hybrid teaching model: sports and developmental education. We worked in 45 classes with 23 students from the $6^{\text {th }}$ year of elementary school. Using the Psychological Basic Needs Questionnaire in Physical Education, we observed that the program indicated improvement in autonomy, reflecting on students' participation and integration during lessons.

Resumen: Analizamos cómo un programa de intervención basado en la enseñanza de deportes colectivos pudo contribuir para motivar a los estudiantes a participar en las clases de Educación Física. La acción intervencionista se sustentó en un modelo híbrido de enseñanza: educación deportiva y desarrollista. Trabajamos en 45 clases con la participación de 23 estudiantes de sexto grado de primaria. A partir del cuestionario de Necesidades Psicológicas Básicas en la Educación Física observamos que el programa indicó una mejora en la autonomía, lo que se reflejó en la participación e integración de los estudiantes en el transcurso de las clases.
*Universidade Estadual de Maringá. Maringá, PR, Brasil. E-mail: luarantescosta@gmail.com; vfmatias@gmail.com; lenamarfiorese@gmail.com

**Universidade do Paraná. UNOPAR. Curitiba, PR, Brasil. E-mail: borsatopassos@gmail.com

Recebido em: 26-07-2016 Aprovado em: 22-07-2017 (c) (1) (8) Licence 


\section{INTRODUÇÃOO}

Durante muito tempo a Educação Física Escolar se viu refém da prática esportiva, evidenciando um modelo de conservação da cultura esportiva institucionalizada, ou seja, os estudos têm demonstrado que a realidade no âmbito escolar apresenta uma prática pedagógica baseada na lógica do rendimento técnico-formal, com 0 ensino dos esportes de cunho eminentemente competitivista (SOUZA; BACCIN, 2009).

Essa realidade desperta ainda mais para um ambiente escolar que suscite um trabalho pedagógico nas aulas de Educação Física Escolar que possa contribuir para o desenvolvimento de ações participativas dos alunos, nas quais esses possam se sentir motivados a interagir e participar, ao mesmo tempo em que Ihes sejam proporcionadas situações esportivas que lhes possibilitem conhecer seus próprios limites a partir das ações durante as atividades realizadas nas aulas.

O estudo realizado por Chicati (2000) indicou que mais de 30\% dos alunos têm um interesse abaixo de regular para frequentar e participar das aulas de Educação Física Escolar. Estar motivado a participar, a realizar tarefas, a integrar-se com e no grupo é um aspecto importante tanto para o desenvolvimento pedagógico nas aulas como para o desenvolvimento individual de cada aluno. Logo, estar motivado é um fator essencial para que haja maior interesse no decorrer das aulas.

Tendo essa compreensão, observamos que nas últimas décadas a motivação dos alunos para a permanência e participação nas aulas tem sido uma temática recorrente, uma vez que se tem a compreensão de que os alunos mais motivados são aqueles que estão sempre aptos a participar e sempre dispostos a superar limites (DECl et al., 1981; GROLNICK; RYAN, 1987; DECl et al., 1991; HAGGER et al., 2003; BARKOUKIS et al., 2014). Nesse desenho a relação professor-aluno passa a se tornar a peça central de toda ação educativa, uma vez que a intervenção do professor que leve 0 aluno a refletir acerca de sua prática possibilita àquele que Ihe sejam evidenciados outros aspectos importantes para o desenvolvimento educativo, como exemplo os aspectos psicológicos evidenciados na Teoria das Necessidades Psicológicas Básicas (DECl; RYAN, 2002), em que um dos objetivos é a motivação dos alunos.

O cenário escolar, em geral, pode apresentar ações docentes diferenciadas, de um lado pode evidenciar e permitir a participação do aluno, instigando-o e motivando-o a romper suas próprias limitações e, de outro, ações de coesão e controle nas ações pedagógicas, acarretando alunos desmotivados e com pouca participação nas aulas. Para retratar essa afirmativa trazemos as contribuições de Cox et al. (2008), que verificaram em seu estudo que, quando o professor apoia e privilegia ações de autonomia para com os seus alunos nas aulas de Educação Física, a motivação desses é amplamente estimulada. Nesse sentido, estudo realizado por Assor et al. (2005) indicou que os professores controladores, que não apoiavam a autonomia, despertavam em seus alunos a raiva e ansiedade, dificultando o relacionamento deles no ambiente escolar.

O excesso de avaliações, pressão social, vigilância e cobrança, tão comuns no ambiente escolar, dificultam o processo de motivação intrínseca, tão necessário para o ser humano. Além disso, enquanto o feedback positivo ajuda a manter sentimentos de competência, o feedback negativo, especialmente quando inserido num contexto de controle, provoca sentimento de frustração, prejudicando a motivação e dificultando o relacionamento (MOURATIDIS et al., 
2008), o que demonstra que os alunos num ambiente controlador podem perder sua autonomia, competência e relacionamento, dimensões evidenciadas nas necessidades psicológicas básicas. Tendo essa compreensão, o desafio deste estudo foi buscar elucidar como se dão na prática os resultados de um trabalho que tem como sustentação o esporte educacional como possibilidade de promover a motivação dos alunos a participarem efetivamente nas aulas de Educação Física. A literatura apresenta um considerável número de estudos que abordam a importância das intervenções pedagógicas motoras sobre ganho em habilidades motoras e esportivas (ARAUJO et al., 2012; MCKENZIE; LOUNSBERY, 2013), mas que há uma carência de um olhar direcionado para a melhoria dos aspectos psicológicos.

Assim, o foco da investigação centrou-se em analisar um programa de intervenção baseado no ensino de esportes estruturado num modelo híbrido de ensino (Modelo de Educação Esportiva e Modelo Desenvolvimentista). O Modelo de Educação Esportiva (MED) é um modelo que procura oferecer aspectos de renovação no ensino dos esportes na escola, investindo em seu potencial educativo, na formação de alunos desportivamente competentes, cultos e entusiastas (SIEDENTOP, 1994). No MED, os alunos realizam as tarefas em equipes com objetivo de desenvolver o sentimento de afiliação, desempenhando diferentes papéis (jogadores, árbitros, jornalistas e dirigentes). Eventos culminantes devem ser desenvolvidos durante o processo de ensino, estimulando o fair play, a cooperação e participação entre os alunos.

Ao longo dos anos, o MED foi alvo de várias publicações científicas, permitindo afirmar que é um modelo consolidado, principalmente no âmbito do desenvolvimento das competências afetivas e sociais (COELHO et al., 2012; MESQUITA; GRAÇA, 2012), pela valorização da cooperação e da inclusão (PEREIRA et al. 2013), e o suporte ao apoio da autonomia dos alunos no processo de ensino e aprendizagem (PERMAN; KARP, 2010). Esses aspectos justificam a escolha do MED na implementação deste estudo, pois nosso objetivo buscava contribuir para o desenvolvimento das necessidades psicológicas básicas dos alunos.

No Modelo Desenvolvimentista (MD), evidencia-se a valorização da estruturação do processo de instrução, decorrente do entrelaçamento da matéria de ensino com os princípios didáticos (RINK, 2010). O MD apresenta uma tipologia de tarefas em complexidade crescente, em que o objetivo primordial é que os alunos possam adquirir novas habilidades motoras (MESQUITA; GRAÇA, 2009) com atividades que permitam o desenvolvimento motor, afetivo e cognitivo, favorecendo a percepção de competência dos alunos, ou seja, estimulando as necessidades psicológicas básicas do ser humano.

Dessa forma, o objetivo desta investigação foi contribuir para que os alunos participassem das aulas de Educação Física a partir da realização do modelo híbrido (MED e MD). A nossa hipótese conceitual é que poderia ocorrer uma melhora na autonomia, competência e relacionamento para as ações cotidianas do universo da Educação Física Escolar.

\section{PERCURSO METODOLÓGICO}

A escola é um espaço de diversidades culturais e realidades diversas, o que nos suscitou a efetivar a experimentação em um espaço educativo que acolhesse em sua realidade uma maior diversidade socioeconômica, cultural e social. Assim, os passos para iniciarmos a implementação seguiram as orientações deliberadas pelo Núcleo de Educação, sendo que a 
primeira ação foi entregar uma carta convite à Chefia do Núcleo Regional de Maringá/PR, que autorizou a realização do estudo e o contato inicial com as escolas participantes.

Devidamente autorizados, os encaminhamentos das ações de implementação se deram na seguinte ordem: a) da escolha do local: tendo o panorama delimitado de busca por uma escola que integrasse alunos de realidades diversas em um mesmo ambiente, chegamos a uma escola da rede estadual de ensino do município de Maringá/PR; os alunos participantes estudaram no ano anterior em escola municipal pública e não tinham vivência do conteúdo ministrado nas aulas de Educação Física, tendo que se adaptar a um novo contexto, novos professores e ambiente diferenciado; apenas três alunos participavam de escolinha de esporte fora do ambiente escolar; a maioria dos alunos $(60 \%)$ chega até a escola com transporte público e $20 \%$ vão caminhando; o IDEB da escola encontra-se em situação de alerta $(4,4)$; b) da seleção da turma: para o processo de seleção da turma participante do programa de intervenção, após considerar a apreciação e disponibilidade da escola a turma foi selecionada aleatoriamente; c) dos alunos participantes: a experimentação prática contou com a participação de 23 alunos regularmente matriculados, resultado da autorização dos seus responsáveis, que assinaram um Termo de Consentimento Livre e Esclarecido, garantindo o sigilo de suas informações pessoais e o uso exclusivo das informações para fins acadêmicos; d) da implementação: a implementação do programa de intervenção foi realizada com 0 6을 ano do ensino fundamental durante dois bimestres nas aulas de Educação Física, o que resultou na aplicação prática de 45 aulas.

A investigação buscou por meio de um estudo quanti-qualitativo descortinar o modo como se desenvolveu o processo de ensino-aprendizagem, implementando estratégias pedagógicas que buscavam a implementação de um modelo de ensino que evidenciasse preocupação pedagógica com a motivação dos alunos.

A implementação das aulas foi estruturada a partir do ensino híbrido de ensino: Modelo de Educação Esportiva (SIEDENTOP, 1994) e Modelo Desenvolvimentista (RINK, 2010). Esses modelos foram escolhidos por evidenciarem um conhecimento amplo do conteúdo, pois concentram suas ações em ensinar os movimentos e gestos técnicos específicos (dimensão procedimental), mas também na importância de compreender a importância da realização destes movimentos (dimensão conceitual), atribuindo valores e atitudes apropriadas à prática dos esportes (dimensão atitudinal) (BARROSO; DARIDO, 2009). Assim, o programa de intervenção (Quadro 1) evidenciou as dimensões conceituais, procedimentais e atitudinais durante as aulas, desenvolvendo atividades propostas para a melhoria da competência, autonomia e relacionamento dos alunos.

Quadro 1 - Esquematização dos conteúdos (esportes coletivos) para o programa de intervenção pedagógica.

\begin{tabular}{|c|c|c|c|}
\hline SÉRIE & CONCEITUAL & PROCEDIMENTAL & ATITUDINAL \\
\hline $6^{\circ}$ ano & $\begin{array}{l}\text { - Características dos } \\
\text { esportes coletivos; } \\
\text { - Ataque e defesa } \\
\text { (direções); } \\
\text { - Igualdade numérica; } \\
\text { - Conceitos iniciais } \\
\text { de inferioridade e } \\
\text { superioridade numérica; } \\
\text { - Tomada de decisão tática. }\end{array}$ & $\begin{array}{l}\text { - Jogos Desenvolvimentistas de Nível II; } \\
\text { - Habilidades com bola (Fundamentos: a) futsal: drible, } \\
\text { passe/recepção e chute; b) basquetebol: drible, passe e } \\
\text { arremesso; c)handebol: drible, passe e arremesso); } \\
\text { - Exercícios de oposição simplificada: 1X0, 2X1 e 3X2; } \\
\text { - Exercícios semelhantes ao jogo formal (1X1, 2X2 e } \\
\text { 3X3). } \\
\text { - Torneios: Futsal de Trio, Basquete de Dupla e } \\
\text { Handebol de Trio. }\end{array}$ & $\begin{array}{l}\text { - Cooperação; } \\
\text { - Autoconceito; } \\
\text { - Respeito; } \\
\text { - Responsabilidade; } \\
\text { - Socialização; } \\
\text { - Autoestima. }\end{array}$ \\
\hline
\end{tabular}

Fonte: os autores. 
O Modelo de Educação Esportiva é uma abordagem de ensino que procura investir seu potencial educativo na formação de alunos que compreendam o sentido do esporte para suas vidas (MESQUITA, 2012; SIEDENTOP, 1994). Neste modelo, os alunos são o centro do processo de ensino, realizando as tarefas em equipes com objetivo de desenvolver o sentimento de afiliação, desempenhando diferentes papéis (jogadores, árbitros, jornalistas e dirigentes). Além disso, no final de cada unidade didática foram realizados eventos culminantes (festival), em que foram entregues premiações para os alunos que participaram de todas as atividades, como arbitragem, fotógrafos, jogadores e jornalistas do evento.

No Modelo Desenvolvimentista valorizamos a estruturação do processo de ensino e instrução, elencando os princípios didáticos e tarefas de complexidade crescente estabelecidas em todos os planos de aula desenvolvidos. Para aumentar a motivação dos alunos nas aulas de Educação Física, Rink (2010) propõe alguns princípios: a) os professores devem encontrar caminhos para estimular os alunos e seus comportamentos positivos; b) os alunos devem perceber a significância e os objetivos daquilo que é necessário ser aprendido; c) os professores devem usar diferentes estratégias de ensino, desafiando e proporcionando autonomia durante as atividades inovadoras (os alunos não deveriam predizer o que os professores realizam nas aulas); d) os professores devem realizar atividades culminantes que permitam aos alunos demonstrar esforços e compreender que todos os indivíduos são iniciantes em algum momento, devendo estabelecer metas desafiadoras, mas realistas; e) 0 ambiente de aprendizagem deve ser orientado à tarefa, sendo o sucesso e fracasso controlado por cada um dos alunos.

Para a avaliação das necessidades psicológicas básicas, antes e após a implementação do programa de intervenção, utilizamos o questionário de Necessidades Psicológicas Básicas na Educação Física Escolar (BPNES), validado para a língua portuguesa (COSTA, 2015). Os dados do questionário do BPNES foram coletados nos horários das aulas de Educação Física ou em horários previamente agendados para a realização. A opção por esse questionário se deu em função de considerarmos essas dimensões essenciais para que os alunos possam se sentir motivados a participar de forma efetiva das aulas de Educação Física Escolar, assim como verificarmos os princípios norteadores da Teoria das Necessidades Psicológicas Básicas (DECl; RYAN, 2002).

O BPNES possui três dimensões relacionadas às necessidades psicológicas básicas: autonomia, competência e relacionamento. 0 questionário verifica a necessidade psicológica básica que predomina no comportamento dos alunos naquele momento, em que a necessidade de autonomia reflete um sentimento de vontade e autoafirmação no comportamento dos alunos; a necessidade de competência refere-se a oportunidades para desenvolver as capacidades dos alunos no contexto escolar; e a necessidade de relacionamento refere-se a situações em que os alunos sentem que possuem uma ligação com outras pessoas significativas. Como o questionário foi respondido pelos alunos numa escala Likert de cinco pontos, realizamos uma equação de ponderação (PEREIRA, 2004) para que os dados quantitativos pudessem ser transformados em qualitativos. Assim, o questionário se manteve originalmente em escala Likert. Entretanto, as respostas dos alunos foram transformadas em índices, representados da seguinte forma: a) -100,00\% a -59,99\% (Índice Muito Baixo); b) -60,00\% a -19,99\% (Índice Baixo); c) -20,00\% a +19,99\% (Índice Médio); d) +20,00\% a +59,99\% (Índice Alto); e) +60,00\% $a+100,00 \%$ (Índice Muito Alto). 
A nossa opção metodológica para a análise dos dados pode ser assim exemplificada: quando um aluno respondeu apenas " 5 " em todos os itens (concordo completamente) nas quatro questões relacionadas à autonomia, seu índice ficava em " $+100,00 \%$ ", podendo ser representado como "Índice Muito Alto". Por outro lado, se respondesse "1" para o item 3, "5" para o item 6, "1" para o item 9 e "5" para o item "12" (todos relacionados à autonomia), verificamos que seu índice ficava em "00,00\%" (Índice Médio). Porém, é necessário observar que, se os cálculos fossem realizados em valores de média comum (como na maioria das vezes), no último exemplo o valor da média seria "4", que poderia ser considerado um valor alto (Likert de 1 a 5), apesar do grande desvio-padrão. Assim, ao realizarmos a opção de utilizarmos a média ponderada acreditamos que as respostas se tornaram mais fidedignas.

Para conhecer as características dos alunos foi utilizado um questionário com questões relacionadas à "prática de atividade física ou escolinhas de esporte", "escola em que o aluno estudou no ano anterior", e "meio de transporte utilizado para deslocamento à escola". Além disso, o diário do professor e as notas de campo contribuíram para analisar as ações pedagógicas durante a implementação do modelo híbrido. Foram registrados no diário do professor os acontecimentos e situações considerados relevantes pelo professor diariamente após o decurso das aulas. As notas de campo foram realizadas no decorrer da implementação do programa de intervenção pedagógica (em qualquer momento considerado oportuno) no sentido de captar informações importantes de cada aula.

O projeto de pesquisa número 236.092 recebeu a aprovação do Comitê de Ética e Pesquisa com Seres Humanos da Universidade Estadual de Maringá, em 3 de março de 2013.

\section{CONTRIBUIÇÕES E LIMITES DO ESPORTE NAS AULAS DE EUCAÇÃO FÍSICA PARA A MOTIVAÇÃO DOS ALUNOS}

O professor é agente de transformação da realidade posta no contexto escolar a partir de sua ação interventiva, na qual se possibilita a dinamicidade do aluno para com as transformações sociais no seu contexto cotidiano (GALVÃO, 2002). Tendo essa compreensão, a organização das intervenções ocorreu durante as aulas de Educação Física: 45 aulas de 50 minutos, as quais foram organizadas com 16 aulas destinadas ao futsal, 14 aulas ao basquetebol, 14 aulas de handebol e uma aula de avaliação final (Quadro 2). Os esportes de invasão (futsal, basquetebol e handebol) foram escolhidos para esta investigação de forma proposital para que pudéssemos, durante o processo de ensino e aprendizagem, pontuar questões importantes para o aprendizado dos alunos, como: a) os objetivos do ataque e da defesa para o alcance dos objetivos do jogo; b) o ensino sobre ataque e defesa com ocupação (invasão) da quadra adversária; c) os aspectos defensivos para buscar o objetivo do jogo (gol ou cesta); d) o trabalho em equipe para se atingir os objetivos do jogo; e e) o relacionamento entre os alunos (da própria equipe ou os colegas "adversários") para a efetivação da organização do jogo. 
Quadro 2 - Conteúdos para o ensino dos desportos coletivos (futsal, basquetebol e handebol) com a utilização de um modelo híbrido (Modelo de Educação Esportiva e Modelo Desenvolvimentista).

\begin{tabular}{|c|c|c|}
\hline Aulas & Componentes do Modelo Desenvolvimentista & $\begin{array}{l}\text { Componentes do Modelo de Educação } \\
\text { Esportiva }\end{array}$ \\
\hline \multicolumn{3}{|c|}{ Futebol de Salão (Futsal) } \\
\hline $1-2$ & Introdução à disciplina de Educação Física & Introdução à disciplina de Educação Física \\
\hline 3-4 & Avaliação diagnóstica (inicial); & $\begin{array}{c}\text { Conhecer os alunos; } \\
\text { Organização das equipes }\end{array}$ \\
\hline $5-6$ & Jogos simplificados & Introdução das regras do trabalho em equipe \\
\hline $7-8$ & $\begin{array}{c}\text { Exercícios Tipo } 1 \text { (passe/recepção); Exercícios } \\
\text { Tipo } 2 \text { (passe e drible); }\end{array}$ & $\begin{array}{l}\text { Responsabilização dos alunos na realização das } \\
\text { tarefas; } \\
\text { Construção do quadro de notícias; }\end{array}$ \\
\hline $9-10$ & Exercícios Tipo 3 (2X1); Exercícios Tipo 4 (1X1); & Organização dos "papéis" dos alunos \\
\hline $11-12$ & $\begin{array}{c}\text { Exercícios Tipo } 1 \text { (passe); Exercícios Tipo } 2 \text { (passe } \\
\text { e chute); }\end{array}$ & $\begin{array}{l}\text { Elaboração do regulamento do evento } \\
\text { culminante }\end{array}$ \\
\hline $13-14$ & Exercícios Tipo 3 (2X1); Exercícios Tipo 4 (3X3); & $\begin{array}{l}\text { Elaboração do "grito" da equipe; } \\
\text { Discussão sobre fair play; }\end{array}$ \\
\hline $15-16$ & \multicolumn{2}{|c|}{$\begin{array}{c}\text { Evento Culminante - Torneio de Futsal 3X3. } \\
\text { Entrega de certificados. }\end{array}$} \\
\hline \multicolumn{3}{|c|}{ Basquetebol } \\
\hline $17-18$ & Jogos simplificados & $\begin{array}{l}\text { Organização das equipes pelos alunos com a } \\
\text { orientação da professora. }\end{array}$ \\
\hline $19-20$ & Habilidades com bola (jogos pré-desportivos). & Introdução das regras do trabalho em equipe \\
\hline $21-22$ & $\begin{array}{l}\text { Exercícios Tipo } 1 \text { (arremesso); Exercícios Tipo } 2 \\
\text { (drible, passe e arremesso); }\end{array}$ & $\begin{array}{l}\text { Responsabilização na realização das tarefas; } \\
\text { Construção do quadro de notícias; }\end{array}$ \\
\hline $23-24$ & Exercícios Tipo 3 (2X1); Exercícios Tipo 4 (2X2); & Organização dos "papéis" \\
\hline $25-26$ & $\begin{array}{l}\text { Exercícios Tipo } 1 \text { (bloqueio de rebote); Exercícios } \\
\text { Tipo } 2 \text { (rebote, passe e arremesso); }\end{array}$ & $\begin{array}{l}\text { Elaboração do regulamento do evento } \\
\text { culminante }\end{array}$ \\
\hline $27-28$ & Exercícios Tipo 3 (3X2); Exercícios Tipo 4 (3X3); & $\begin{array}{l}\text { Elaboração do "grito" da equipe; } \\
\text { Discussão sobre fair play; }\end{array}$ \\
\hline $29-30$ & \multicolumn{2}{|c|}{$\begin{array}{l}\text { Evento Culminante - Torneio de Basquetebol 2X2. } \\
\text { Entrega de certificados. }\end{array}$} \\
\hline \multicolumn{3}{|c|}{ Handebol } \\
\hline 31 & Jogos simplificados & $\begin{array}{l}\text { Organização das equipes pelos próprios alunos } \\
\text { com a supervisão do professor. }\end{array}$ \\
\hline $32-33$ & Habilidades com bola (jogos pré-desportivos). & Introdução das regras do trabalho em equipe \\
\hline $34-35$ & $\begin{array}{c}\text { Exercícios Tipo } 1 \text { (arremesso); Exercícios Tipo } 2 \\
\text { (drible, passe e arremesso); }\end{array}$ & $\begin{array}{l}\text { Responsabilidade na realização das tarefas; } \\
\text { Construção do quadro de notícias; }\end{array}$ \\
\hline $36-37$ & Exercícios Tipo 3 (2X1); Exercícios Tipo 4 (2X2); & Organização dos "papéis"; \\
\hline $38-39$ & $\begin{array}{c}\text { Exercícios Tipo } 1 \text { (arremesso com progressão); } \\
\text { Exercícios Tipo } 2 \text { (drible, passe e arremesso com } \\
\text { progressão); }\end{array}$ & $\begin{array}{l}\text { Elaboração do regulamento do evento } \\
\text { culminante; }\end{array}$ \\
\hline $40-41$ & Exercícios Tipo 3 (3X2); Exercícios Tipo 4 (4X4); & $\begin{array}{l}\text { Elaboração do "grito" da equipe; } \\
\text { Discussão sobre fair play; }\end{array}$ \\
\hline $42-44$ & \multicolumn{2}{|c|}{$\begin{array}{l}\text { Evento Culminante - Torneio de Handebol 3X3; } \\
\text { Entrega de certificados; }\end{array}$} \\
\hline 45 & \multicolumn{2}{|c|}{ Avaliação final. } \\
\hline
\end{tabular}


A construção do plano de unidade, verificado no Quadro 2, e dos planos de aula nos permitiu o planejamento dos conteúdos das aulas. Com a utilização do modelo híbrido (Modelo de Educação Esportiva e Modelo Desenvolvimentista) a nossa preocupação foi fomentar a participação efetiva de todos os alunos, por meio das dimensões conceitual, procedimental e atitudinal, desenvolvendo ainda a capacidade de jogo por meio da melhoria das habilidades específicas - ensino da técnica, e do estímulo à tomada de decisão - ensino da tática (GRAÇA; MESQUITA, 2013; MESQUITA, 2013).

Os alunos do 60 ano apresentaram índice médio de autonomia antes da realização do programa de intervenção, e após o programa apresentaram um índice alto de autonomia. Outro aspecto relevante é que todos os alunos que participaram do programa de intervenção não obtiveram índice "muito baixo" ou "baixo" em nenhum momento em nenhuma das necessidades psicológicas básicas (Quadro 3).

Quadro 3 - Necessidades psicológicas básicas do ser humano (autonomia, competência e relacionamento) dos alunos participantes do programa de intervenção (PI) de ensino dos esportes coletivos de invasão.

\begin{tabular}{|c|c|c|c|c|c|c|}
\hline \multirow{2}{*}{$\begin{array}{c}\text { Necessidades } \\
\text { Psicológicas para } \\
\text { o ser humano }\end{array}$} & \multicolumn{2}{|c|}{ Alunos do 60 ano participantes do programa de intervenção } \\
\cline { 2 - 7 } & Antes PI & Depois PI & Antes PI & Depois PI & Antes PI & Depois PI \\
\hline Autonomia & Médio & Alto & Baixo & Médio & Médio & Alto \\
\hline Competência & Muito Alto & Muito Alto & Alto & Alto & Muito Alto & Muito Alto \\
\hline Relacionamento & Alto & Alto & Alto & Muito Alto & Alto & Alto \\
\hline
\end{tabular}

Fonte: os autores.

Após o programa de intervenção, as meninas apresentaram um índice alto de autonomia. Por outro lado, o seu nível de competência se manteve em índices "muito alto" antes e após o programa de intervenção. Em relação à competência e relacionamento, os índices também se mantiveram altos e muito altos para todos os alunos. Ao considerar os índices de autonomia, competência e relacionamento entre os participantes nas aulas de Educação Física, os resultados do estudo demonstraram que os alunos que haviam iniciado 0 60 ano (segundo ciclo do ensino fundamental) aumentaram sua autonomia após o programa de intervenção (Quadro 3), revelando a importância de se iniciar o segundo ciclo com atividades apropriadas e metodologias de ensino adequadas (NUNOMURA et al., 2015), em que o aluno possa melhorar suas necessidades psicológicas básicas com a prática implementada pelos professores. Entretanto, apesar da proposta pedagógica evidenciar em suas atividades a autonomia dos alunos, sabe-se que outros aspectos podem ter favorecido a melhoria dessa necessidade psicológica básica. Essa é uma limitação de uma investigação de cunho qualitativo, com a natureza de estudo de caso, que não tem a intenção de controlar outros aspectos intervenientes no desenvolvimento psicológico dos alunos. Na transição do ensino fundamental (primeiro ciclo) para o segundo ciclo, os alunos participantes da investigação já apresentavam um nível de necessidades psicológicas básicas (autonomia, competência e relacionamento) bastante satisfatórias, o que poderia revelar que as iniciativas pedagógicas no ensino fundamental (primeiro ciclo) foram adequadas. Investigações realizadas no contexto escolar demonstraram que proporcionar aos alunos a possibilidade de escolha normalmente aumenta a motivação intrínseca (BAO; LAM, 2008), o que pode ter ocorrido no contexto do primeiro ciclo dos alunos participantes. A satisfação da necessidade de autonomia proporciona 
a melhoria da motivação intrínseca dos alunos, pois conseguem atribuir a si mesmos as causas de seu sucesso ou fracasso.

Em uma recente meta-análise de estudos sobre o processo de escolha dos alunos, foi verificado que a motivação intrínseca pode ser melhorada quando estes escolhem aquilo que desejam para sua vida escolar, ou seja, possuem autonomia (PATALL; COOPER; ROBINSON, 2008). Parece que quando os alunos estão em contextos sociais nos quais se sentem seguros e compreendidos, estes desejam internalizar os conhecimentos, repetindo práticas daqueles que os rodeiam, inclusive de seus professores. Quando os suportes para relações sociais são atrelados ao apoio à autonomia e competência, ocorre a integração de atividades aumentando a motivação intrínseca (RYAN; DECI, 2000). Segundo os autores, atualmente, as atividades realizadas nas escolas possuem aspectos que buscam controlar os alunos para promover 0 respeito às regras, que, na maioria das vezes, são elaboradas sem a participação dos alunos, dificultando o processo de autonomia.

Um dos aspectos que parece favorecer o sentimento de competência dos alunos está relacionado ao feedback proporcionado durante a realização das aulas de Educação Física, que devem ser planejadas antecipadamente para realizar avaliação de caráter formativo. A manutenção dos índices de competência dos alunos participantes do estudo pode ser considerado algo positivo, pois o contexto de mudança do primeiro para o segundo ciclo poderia ter diminuído a percepção de competência dos alunos, visto que ocorre uma alteração do ambiente escolar, dos conteúdos realizados nas aulas e de todo o contexto de mudanças ocorridas durante esse processo. Mouratidis et al. (2008) salientam a importância do feedback positivo nos momentos de mudança: enquanto o feedback positivo ajuda a manter sentimentos de competência, o feedbacknegativo, especialmente quando inserido num contexto de controle, provoca sentimento de frustração, prejudicando a motivação intrínseca.

Dessa forma, ao estimular a compreensão da importância de cada conteúdo realizado, o professor pesquisador percebeu por meio das observações realizadas durante as aulas que as alunas aceitavam as atividades realizadas e assim acreditavam que estas eram realizadas de acordo com seus desejos e interesses. As meninas, ao compreenderem a importância dos conteúdos, demonstravam nos diálogos informais e na sua participação que a motivação, mesmo com dificuldades na realização de cada atividade, era muito aumentada no decorrer das aulas (COSTA et al., 2016). Assim, os resultados demonstraram a necessidade de se iniciar novas metodologias de ensino no início do segundo ciclo, minimizando os efeitos negativos de uma prática diferenciada no decorrer do processo pedagógico.

Em estudo realizado por Taylor et al. (2008), os autores destacaram o fato de que os professores de Educação Física influenciaram a motivação dos alunos, sendo o planejamento das aulas fundamental neste aspecto. $O$ fato de que a partir do programa de intervenção os alunos apresentarem índices altos e muito altos de autonomia, competência e relacionamento evidenciou o quanto as aulas de Educação Física puderam contribuir para aumento e manutenção das necessidades psicológicas básicas dos alunos, e, consequentemente, para sua motivação. Em estudo realizado com alunos ingleses e chineses, os autores identificaram que houve uma melhoria na dedicação dos alunos quando o professor criava um ambiente favorável à autonomia (TAYLOR; LONSDALE, 2010). Desta forma, para Ryan e Deci (2009), os contextos sociais podem apoiar ou dificultar este processo que deveria ser natural para 0 ensino e a aprendizagem nas aulas de Educação Física Escolar. 
Ao analisar a percepção de suporte para as necessidades psicológicas básicas dos alunos do ensino médio, Legault et al. (2006) demonstraram que as relações de apoio de pais, professores e amigos podem melhorar o desempenho escolar e a autoestima, evitando problemas de comportamento e intenções de abandono da escola. Segundo os autores, a compreensão da motivação no ambiente escolar pode proporcionar implicações para os currículos na Educação Física, além de facilitar a prática pedagógica dos professores.

Assim, um aspecto a destacar é que todos os alunos não obtiveram índices "muito baixos" ou "baixos" em nenhuma das necessidades psicológicas básicas, o que poderia evidenciar que, em geral, conseguem estabelecer metas intrínsecas que satisfazem as necessidades psicológicas básicas, o que poderia demonstrar autoestima e vínculos afetivos nos participantes do estudo. Ao contrário, quando os alunos estabelecem metas extrínsecas, estas necessidades não são satisfeitas. Quando isto ocorre, a aprendizagem dos alunos é superficial, aumentando a ansiedade e reduzindo o envolvimento e persistências nas tarefas (VANSTEENKISTE; LENS; DECI, 2006).

\section{CONSIDERAÇÕES FINAIS}

Observamos durante o programa de intervenção pedagógica utilizando um momento híbrido de ensino que as aproximações entre o esporte educacional nas aulas de Educação Física Escolar podem provocar mudanças individuais nas ações dos alunos, contribuindo para que os avanços pessoais possam ser refletidos nas ações coletivas durante as aulas ou outras ações que remetem ao cotidiano escolar.

Considerando a intervenção pedagógica realizada com os alunos do $6^{\circ}$ ano (segundo ciclo do ensino fundamental), observamos que estes aumentaram sua autonomia, sendo importante destacar que para alunos que estão iniciando em um contexto desconhecido, em uma nova realidade escolar, um novo ambiente, novos professores e estrutura física diferenciada, a utilização de um programa de intervenção baseado em um modelo híbrido parece ter influenciado a motivação dos alunos, principalmente no que se refere à autonomia nas meninas. Entretanto, não podemos afirmar que apenas a preocupação em estruturar um modelo híbrido é capaz de melhorar a autonomia dos alunos, pois outros fatores, como as relações sociais e o início da adolescência poderiam melhorar esse processo, sendo esta uma limitação de estudos que propõe caminhos diferenciados para a melhoria do trabalho pedagógico.

Como implicação prática, acreditamos na necessidade de apresentar os resultados para as instituições responsáveis pela oferta desta disciplina nas escolas do ensino fundamental. Dessa forma, poderíamos contribuir para o estabelecimento de um planejamento mais apropriado nas aulas de Educação Física, preocupadas com os interesses dos alunos, o que poderia aumentar a motivação intrínseca e proporcionar uma avaliação do trabalho pedagógico do professor. 


\section{REFERÊNCIAS}

ARAUJO, Mauricio Pires de et al. Contribuição de diferentes conteúdos das aulas de educação física no ensino fundamental I para o desenvolvimento das habilidades motoras fundamentais.

Revista Brasileira de Medicina do Esporte, v. 18, p. 153-157, 2012.

ASSOR, Avi et al. Directly controlling teacher behaviors as predictors of poor motivation and engagement in girls and boys: The role of anger and anxiety. Learning and Instruction, v. 15, p. 397-413, 2005.

BAO, Xue Hua; LAM, Shui-fong. Who makes the choice? Rethinking the role of autonomy and relatedness in Chinese children's motivation. Child Development, v. 79, p. 269-283, 2008.

BARKOUKIS, Vassilis et al. The relation between student motivation and student grades in physical education: A 3-year investigation. Scandinavian Journal of Medicine \& Science in Sports, v.24, n 5, p. e406-414 2014.

BARROSO, André Luis Ruggiero; DARIDO, Suraya Cristina. A pedagogia do esporte e as dimensões dos conteúdos. Revista da Educação Física/UEM, v. 20, n. 2, p. 281-289, 2009.

CHICATI, Karen Cristina. Motivation in physical education classes of senior high school grades. Revista da Educação Física/UEM, v. 11, n. 1, p. 97-105, 2000.

COELHO, Irene et al. Ensinar e aprender o atletismo com o Modelo de Educação Desportiva: Relatos de uma professora e dos seus alunos. Revista Portuguesa de Ciências do Desporto, v. 12, n. 1, p. 13-30, 2012.

COSTA, Luciane Cristina Arantes da. Influência de um programa de ensino de esportes coletivos de invasão na motivação e desempenho motor de escolares no ensino fundamental. 2015. 196 f. Tese (Doutorado) - Programa de Pós-Graduação Associado em Educação Física UEM-UEL, Maringá, 2015.

COSTA, Luciane Cristina Arantes da et al. Teaching invasive team sports in the school environment: from theory to practice from the perspective of a hybrid model. Revista da Educação Física/UEM, v. 27, n. 2, p. 161-168, 2016.

COX, Anne E.; SMITH, Alan L.; WILLIAMS, Lavon. Change in physical education motivation and physical activity behavior during middle school. The Journal of Adolescent Health, v. 43, p. 506-513, 2008.

DECl, Edward L.; RYAN, Richard M. Handbook of self-determination research. Rochester: University of Rochester, 2002.

$\mathrm{DECl}$, Edward L. et al. An Instrument to assess adults' orientations toward control versus autonomy with children: Reflections on intrinsic motivation and perceived competence. Journal of Educational Psychology, v. 73, p. 642-650, 1981.

DECI, Edward L. et al. Motivation and Education: The Self-Determination Perspective. Educational Psychologist, v. 26, n. 3, p. 325-346, 1991.

GALVÃO, Zenaide. Educação Física escolar: a prática do bom professor. Revista Mackenzie de Educação Física e Esporte, v. 1, n. 1, p. 65-72, 2002. 
GRAÇA, Amândio; MESQUITA, Isabel. Modelos e concepções de ensino dos jogos desportivos. In: TAVARES, Fernando. Jogos desportivos coletivos: ensinar a jogar. Porto: FADEUP, 2013. p. 9-54.

GROLNICK, Wendy S.; RYAN, Richard M. Autonomy in children's learning: An experimental and individual differences investigation. Journal of Personality and Social Psychology, v. 52, n. 5, p. 890-898, 1987.

HAGGER, Martin S. et al. The Processes by Which Perceived Autonomy Support in Physical Education Promotes Leisure-Time Physical Activity Intentions and Behavior: A Trans-Contextual Model. Journal of Educational Psychology, v.4, n. 95, p. 784-795, 2003.

LEGAULT, Lisa; GREEN-DEMERS, Isabelle; PELLETIER, Luc G. Why do high school students lack motivation in the classroom? Toward an understanding of academic motivation and social support. Journal of Educational Psychology, v. 98, p. 567-582, 2006.

MCKENZIE, Thomas; LOUNSBERY, Monica. Physical education teacher effectiveness in a public health context. Research Quarterly for Exercise and Sport, n. 84, p. 419-430, 2013.

MESQUITA Isabel. Fundar o lugar do desporto na escola através do Modelo de Educação Desportiva. In: MESQUITA Isabel, BENTO Jorge O. (eds.). Professor de Educação Física: fundar e dignificar a profissão. Belo Horizonte: Casa da Educação Física, 2012. p. 177206.

MESQUITA, Isabel. Perspectiva Construtivista da aprendizagem no ensino do jogo. In: NASCIMENTO, Juarez Vieira do; RAMOS, Valmor; TAVARES, Fernando. Jogos desportivos: formação e investigação. Florianópolis: UDESC, 2013. p. 103-132.

MESQUITA, Isabel; GRAÇA, Amândio. Modelos instrucionais no ensino do desporto. In: ROSADO, A.; MESQUITA, I. (Eds.). Pedagogia do Desporto: Lisboa: Edições FMH, 2009. p. 39-68.

MOURATIDIS, Athanasios et al. The Motivating Role of Positive Feedback in Sport and Physical Education: Evidence for a Motivational Model. Journal of Sport \& Exercise Psychology, v. 30, n. 2, p. 240-268, 2008.

PATALL, Erika; COOPER, Harris; ROBINSON, Jorgianne. The effects of choice on intrinsic motivation and related outcomes: A meta-analysis of research findings. Psychological Bulletin, v. 134, p. 270-300, 2008.

PEREIRA, Paulo. Noções de estatística: com exercícios para administração e ciências humanas. Campinas: Papirus, 2004.

PEREIRA, Augusto et al. Estudo comparativo entre o Modelo de Educação Desportiva e o Modelo de Instrução Direta no ensino de habilidades técnico-motoras do atletismo nas aulas de Educação Física. Revista Portuguesa de Ciências do Desporto, v. 13, p. 29-43, 2013.

PERLMAN Dana; KARP Grace. A self-determined perspective of the sport education model. Physical Education and Sport Pedagogy, v. 15, n. 4, p. 401-418, 2010.

RINK, Judith. Teaching physical education. 6. ed. New York: McGraw-Hill , 2010.

RYAN, Richard; DECl, Edward. Self-determination theory and the facilitation of intrinsic motivation, social development, and well-being. American Psychologist, v. 55, p. 68-78, 2000. 
RYAN, Richard; DECl, Edward. Promoting Self-Determined School Engagement: Motivation, Learning, and Well-Being. In: WENTZEL, Kathryn R. ; WIGFIELD, Allan. Handbook of motivation at school. New York: Routledge, 2009. p. 171-196.

SIEDENTOP, Daryl. Sport education: quality PE through positive sports experiences. Champaign: Human Kinetics, 1994.

SOUZA, Maristela da Silva; BACCIN, Ecléa Vanessa Canei. A técnica no ensino dos esportes: relações entre o campo de conhecimento das ciências sociais e das ciências naturais.

Movimento, v. 15, n. 3, p. 127-143, 2009.

TAYLOR, Ian; NTOUMANIS Nikos; STANDAGE, Martyn. A Self-Determination Theory Approach to Understanding the Antecedents of Teachers' Motivational Strategies in Physical Education. Journal of Sport \& Exercise Psychology, v. 30, n. 1, p. 75-94, 2008.

TAYLOR, Ian; LONSDALE, Chris. Cultural Differences in the Relationships among Autonomy Support, Psychological Need Satisfaction, Subjective Vitality, and Effort in British and Chinese Physical Education. Journal of Sport \& Exercise Psychology, v. 32, n. 5, p. 655-673, 2010.

VANSTEENKISTE, Maarten; LENS, Willy; DECI, Edward. Intrinsic versus extrinsic goal contents in self-determination theory: Another look at the quality of academic motivation. Educational Psychologist, n. 41, p. 19-31, 2006. 
